\title{
Sustainable Machining Processes through Optimization of Process Parameters
}

\section{OGEDENGBE Temitayo Samson}

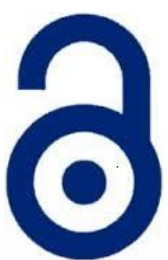 \\ Received: 05 November 2018 \\ Accepted: 24 December 2018 \\ Published: 01 March 2019 \\ Publisher: Deer Hill Publications \\ (C) 2019 The Author(s) \\ Creative Commons: CC BY 4.0
}

\begin{abstract}
Machining processes are a vital part of manufacturing activities in major industries that contributes to the growth of the economy. They mostly require high amount of electrical energy to power the various support modules installed on machine tools. Carrying out machining activities with a view to reducing energy consumption will therefore result in a lowered cost of production for manufactured products. Previous studies on some energy-saving methods adopted by researchers and the limitations faced in the reduction of energy consumption have been discussed. In this work, the effect of process parameters in the conservation of energy during machining processes was experimented. Minitab 16 was used to design the experiment and a 9-run orthogonal array was generated. The machining parameters were cutting speed $(80-120 \mathrm{~m} / \mathrm{min})$, feed $(0.05-0.07 \mathrm{~mm} / \mathrm{rev})$ and depth of cut $(0.1-0.3 \mathrm{~mm})$. A high carbon steel bar was machined using high speed steel tool and the energy consumed during the machining process was measured. Energy $(28.67 \mathrm{kw} / \mathrm{hr})$ was consumed during machining at $0.005 \mathrm{~mm} / \mathrm{rev}$ and $0.3 \mathrm{~m}$. Energy $(12.83 \mathrm{kw} / \mathrm{hr}) \mathrm{was}$ consumed while machining at $0.07 \mathrm{~mm} / \mathrm{rev}$ and $0.1 \mathrm{~m}$. The energy consumed changed with machining parameters. These results showed that much energy could be saved by optimizing parameters before machining.
\end{abstract}

Keywords: Energy consumption, Machine tools, Machining processes, Parameters

\section{INTRODUCTION}

The manufacturing sector comprises some of the largest energy consumers worldwide [1]. Over 60\% of the energy consumed in the industries is accounted for by manufacturing industries [2]. These industries basically use electric power for the transformation of materials into products [3]. Hence, they require a large amount of electrical energy which increases the cost of production for such companies. Therefore, companies have to identify ways to reduce the energy consumed during manufacturing of a given product so as to continue to produce especially at reduced cost [4]. The reduction in cost has largely been the driver for recent studies on energy reduction in the manufacturing sector for the development of more energy-efficient machining processes [5; 6]. Machining is one of the most fundamental and important manufacturing processes that is widely used in manufacturing industries [1,7]. Machining is the process of cutting a material into a desired shape and size using a controlled material-removal process [8]. Recent non-conventional machining processes make use of Computer Numerical Control (CNC) machines to fabricate parts [8]. NC machines control the movements of machine tools through direct insertion of coded instructions into the system as numbers and letters [9]. It is therefore important to note that NC machining plays an important role in the metal-cutting industry. However, metal cutting consumes a large amount of energy which can be attributed to the process of material removal and also to the various components that contributes to the efficient operation of the machine tool [10]. Energy conservation during machining processes has become of more interest to researchers recently. This is because the conservation of energy during machining which is a key element of manufacturing processes will bring about lower costs of products. A reduction in cost of product will result in greater productivity. There is therefore a need to study the possibility of conservation of energy during machining to ensure an increase in profit margins of production companies. Energy demand of a machine tool can be categorized into two broad groups, namely, constant energy components and variable energy components [4]. Where the constant components (i.e fans, lightings computer system etc.) consume a constant amount of energy which does not depend on the process parameter selected, the variable components largely depend on the process parameter selected. Some of the studies

\author{
T. S. Ogedengbe $\mathbb{x}$ \\ Department of Mechanical and Automotive Engineering \\ Elizade University, Ilara-Mokin \\ Ondo State, Nigeria \\ E-mail: temitayo.ogedengbe@elizadeuniversity.edu.ng
}

Reference: Ogedengbe, T. S. (2019). Sustainable Machining Processes Through Optimization of Process Parameters. International Journal of Engineering Materials and Manufacture, 4(1), 22-26. 
on energy conservation during machining are hereafter discussed. A study on automated monitoring of machine tools specifically analysing the energy consumption of the machines has been done [11]. It was reported that process control was a key factor for energy consumption. A study on the possible improvements in energy efficiency of machine tools with Diamond-Like Carbon (DLC) deposited tools has been carried out [12]. Results showed that the method was able to reduce the cutting power consumption of the machine by $36 \%$. The optimization of machining processes from the perspective of energy consumption has also been attempted [13]. It was opined that machining parameters, cutting tools and workpiece materials influence the rate of energy consumption during machining processes. There is a need to further consider the possibility of a conservation of energy through the optimization of process parameters. This work is therefore an attempt to conserve energy by reduction of the energy consumed during machining processes.

\section{METHODOLOCY}

\subsection{Machine and Tools}

The experiment was carried out on a Colchester Triumph model 2000 conventional lathe machine with a 3-jaw chuck as shown in Figure 1. The workpiece material was a high carbon steel bar and the tool used for the experiment was High Speed Steel (HSS). The choice of high carbon steel was informed by the higher difficulty in machining the steel as compared to other materials (e.g. mild steel) used in fabrication of parts. HSS was selected because it was cheaper and easily accessible compared to other tools. The surface roughness was measured with a profilometer while the power consumed was measured using multimeters.

\subsection{Experimental Procedure}

The workpiece used for this experiment was a high carbon steel material. Table 1 shows the result of the compositional analysis for the workpiece material. Figure 2 shows the set up for the experimental process carried out on the lathe machine. The process parameters used for the experiment as given in Table 2 were cutting speed, feed rate and depth of cut. The process parameters were selected based on literature and machine constraints. A low feed was used to ensure a longer period of machining to sufficiently measure energy consumed. Taguchi orthogonal array from Minitab 16 software was used to design the experiment resulting in a 9-experimental run mix with the three factors. The smaller-is-better design option was adopted in the analysis of Signal-to-Noise (SN) ratio for the energy consumed during machining process as recommended by [14]. The energy consumed during the machining process was measured with the use of multi-meters connected in series and parallel to capture the current and voltage respectively. The resulting values where thereafter used to compute the energy consumed using equations 1 and 2 .

$$
\begin{aligned}
& \text { Power }=\sqrt{3} \mathrm{Vl} \\
& \text { Energy Consumed }=\text { Power } x \text { Time }
\end{aligned}
$$

Table 1: Chemical composition of High Carbon Steel Sample

\begin{tabular}{ccc}
\hline S/N & Element & \% Composition \\
\hline 1 & $\mathrm{Fe}$ & 98.07 \\
2 & $\mathrm{Si}$ & 0.510 \\
3 & $\mathrm{Cr}$ & 0.054 \\
4 & $\mathrm{~S}$ & 0.045 \\
5 & $\mathrm{P}$ & 0.032 \\
6 & $\mathrm{Sb}$ & 0.0008 \\
7 & $\mathrm{Nb}$ & 0.0013 \\
8 & $\mathrm{~W}$ & 0.0032 \\
9 & $\mathrm{~V}$ & 0.0007 \\
10 & $\mathrm{Mo}$ & 0.022 \\
11 & $\mathrm{Mn}$ & 0.65 \\
12 & $\mathrm{C}$ & 0.54 \\
13 & $\mathrm{Ni}$ & 0.024 \\
14 & $\mathrm{~Pb}$ & 0.0016 \\
15 & $\mathrm{Cu}$ & 0.060 \\
16 & $\mathrm{Ti}$ & 0.0009 \\
\hline
\end{tabular}



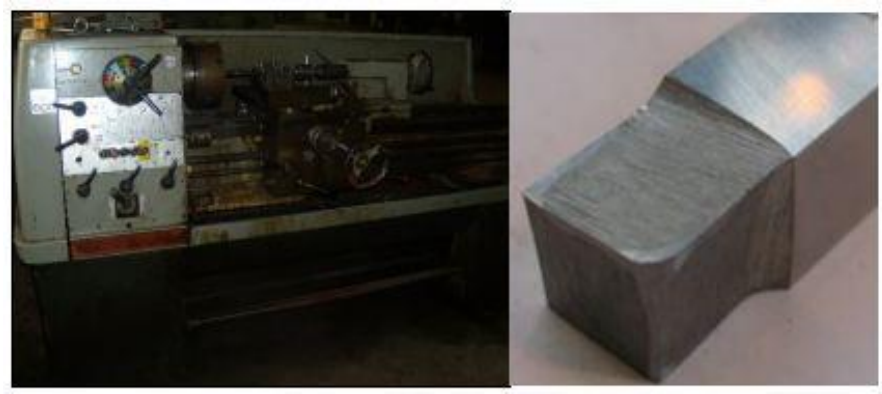

Figure 1: Colchester Lathe machine and HSS tool

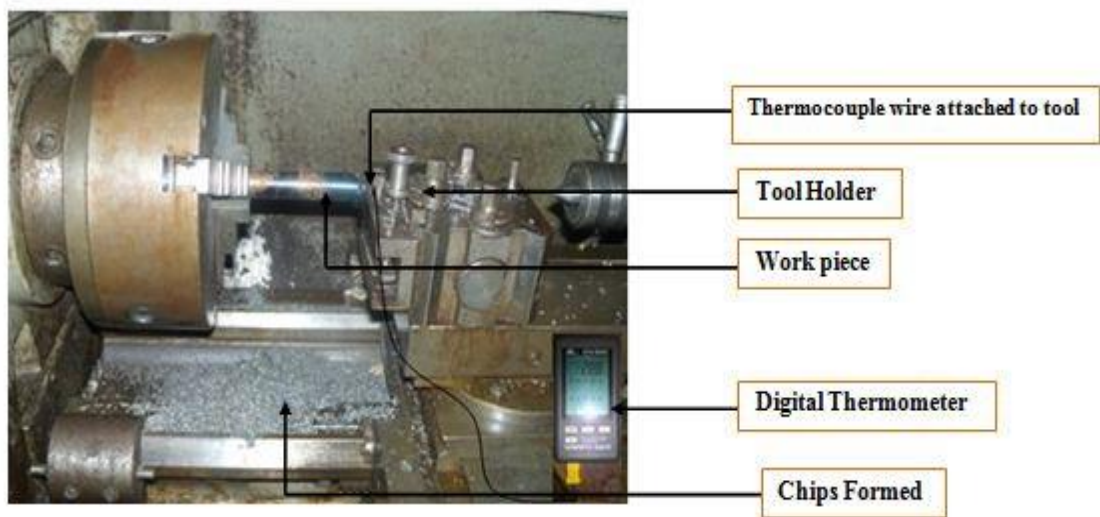

Figure 2: Experimental Set-up

Table 2: Machining Parameters for Experiments

\begin{tabular}{cccc}
\hline Factor & \multicolumn{3}{c}{ Level } \\
\cline { 2 - 4 } & 1 & 2 & 3 \\
\hline Speed $(\mathrm{m} / \mathrm{min})$ & 80 & 100 & 120 \\
Feed rate $(\mathrm{mm} / \mathrm{rev})$ & 0.05 & 0.06 & 0.07 \\
Depth of cut $(\mathrm{mm})$ & 0.1 & 0.2 & 0.3 \\
\hline
\end{tabular}

Table 3: Orthogonal array for machining experiment

\begin{tabular}{cccc}
\hline Run & \multicolumn{3}{c}{ MACHINING PARAMETRS } \\
\cline { 2 - 4 } & $\begin{array}{c}\text { SPEED } \\
(\mathrm{m} / \mathrm{min})\end{array}$ & $\begin{array}{c}\text { FEED } \\
(\mathrm{mm} / \mathrm{min})\end{array}$ & $\begin{array}{c}\text { DOC } \\
(\mathrm{mm})\end{array}$ \\
\hline 1 & 80 & 0.05 & 0.1 \\
2 & 80 & 0.06 & 0.2 \\
3 & 80 & 0.07 & 0.3 \\
4 & 100 & 0.05 & 0.2 \\
5 & 100 & 0.06 & 0.3 \\
6 & 100 & 0.07 & 0.1 \\
7 & 120 & 0.05 & 0.3 \\
8 & 120 & 0.06 & 0.1 \\
9 & 120 & 0.07 & 0.2 \\
\hline
\end{tabular}




\section{RESULTS AND DISCUSSIONS}

The result gotten after the machining is as shown in Figure 4. The highest amount of energy was consumed $(28.67 \mathrm{kw} / \mathrm{Hr})$ during run 7 at a low feed rate of $0.05 \mathrm{~mm} / \mathrm{min}$ and a high depth of cut of $0.3 \mathrm{~m}$. The lowest energy consumption $(12.83 \mathrm{kw} / \mathrm{Hr})$ was also recorded at run 6 with feed rate and depth of cut of $0.07 \mathrm{~mm} / \mathrm{min}$ and $0.1 \mathrm{~mm}$ respectively. Also, as shown in Figure 6 , at values of highest speed of $120 \mathrm{~m} / \mathrm{min}$ and highest feed rate of $0.07 \mathrm{~mm} / \mathrm{min}$ obtained at run 9 with a MRR of $488,850.82 \mathrm{~mm}^{3} / \mathrm{min}$, a very low amount of energy was consumed. These results agree with [15]. The analysis of the $\mathrm{S} / \mathrm{N}$ ratio as shown in Figure 5 indicates that at higher values of cutting speed, the average $S / N$ ratio is higher which is preferable. The analysis also indicates that a higher cutting speed resulted in a higher energy consumption. However, depth of cut and feed rate did not contribute significantly to the consumption of energy.

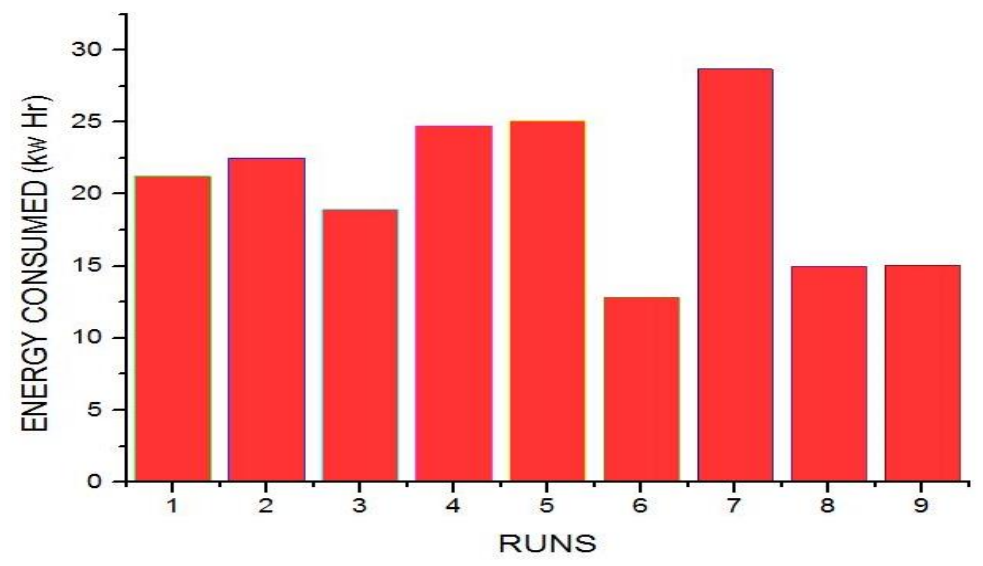

Figure 4: Energy consumed during Runs

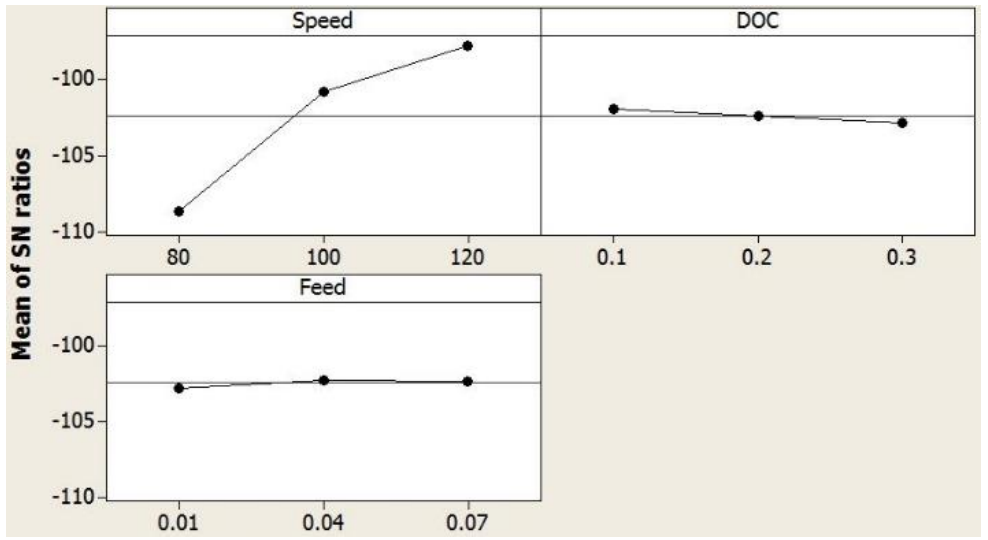

Figure 5: Signal-to-Noise analysis for parameters.

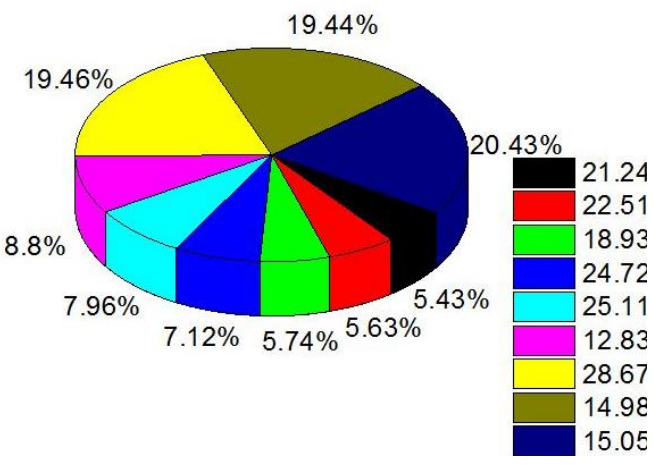

Figure 6: MRR and Energy Consumed analysis during machining. 


\section{CONCLUSIONS}

The aim of this study was to optimize process parameters for conservation of energy. The following conclusions have been reached from the results and findings after the study.

- At highest machining speed $(120 \mathrm{~m} / \mathrm{min})$, lowest energy is consumed.

- Depth of cut has no significant effect on rate of consumption of energy during machining.

- Energy can be conserved by the optimization of process parameters during machining.

\section{ACKNOWLEDGEMENT}

The authors are grateful for generous support from the Central Engineering Workshop, University of llorin, Kwara State, Nigeria and Central Engineering Laboratory/Workshop, Elizade University, Ilara-Mokin, Ondo State, Nigeria where this research was been conducted.

\section{REFERENCES}

1. Moradnazhad M. and Unver H.O. (2016), Energy efficiency of machining operations: A review, Proceedings of Institution of Mechanical Engineers, Part B Journal of Engineering Manufacture 231(11). DOI: $10.1177 / 0954405415619345$

2. Zhou LR, Li JF and Li FY (2016), Energy consumption model and energy efficiency of machine tools: a comprehensive literature review. J Clean Prod; 112: 3721-3734.

3. Arif M., lan A. S. and Olcay A. (2014), A model to determine the optimal parameters in a machining process for the most profitable utilization of machining energy, Proceedings of the Institution of Mechanical Engineers, Part B: Journal of Engineering Manufacture, DOI: 10.1177/0954405414527960

4. Diaz N, Helu M, Jarvis A (2009), Strategies for minimum energy operation for precision machining. In: Proceedings of the Machine Tool Technologies Research Foundation (MTTRF) annual meeting, Shanghai, China.

5. Fang K., Uhan N., Zhao F. (2011), A new shop scheduling approach in support of sustainable manufacturing. In: Proceedings of the 18th CIRP international conference on life cycle engineering, Technische Universita" $t$ Braunschweig, Braunschweig, Germany, pp. 305-310.

6. Duflou J.R, Sutherland J.W, Dornfeld D (2012), Towards energy and resource efficient manufacturing: a processes and systems approach. CIRP Ann: Manufacturing Technology; 61: 587-609.

7. Ogedengbe T. S., Abdulkareem S., Aweda J. O. (2018), Effect of Coolant Temperature on Machining Characteristics of High Carbon Steel, Covenant Journal of Engineering Technology (Special Edition), Vol 1, No 1, Available at https://journals.covenantuniversity.edu.ng/index.php/cjetse/article/view/812

8. Abdulkareem S., Ogedengbe T.S., Aweda J.O, Khan A.A (2017), Comparative Analysis of AISI 1050 Steel Using N5-Soluble Oil and Arachis Oil in Metal Cutting Operation, Proceedings of the 30th AGM and International Conference of the Nigerian Institution for Mechanical Engineers.

9. Kalpakjian, S. and Schmid, S. Manufacturing engineering and technology, (1999) (Addison-Wesley Publishing Company, Boston, Massachusetts).

10. He Y., Liu F., Wu T., Zhong F-P, and Peng B. (2010), Analysis and estimation of energy consumption for numerical control machining, Proceedings of NIMechE Vol. 226 Part B: J. Engineering Manufacture. DOI: $10.1177 / 0954405411417673$

11. Vijayaraghavan, A., Dornfeld, D., (2010). Automated energy monitoring of machine tools. CIRP Annals Manufacturing Technology 59, pp. 21-24.

12. Zolgharni, M., Jones, B.J., Bulpett, R., Anson, A.W. and Franks, J., (2008), Energy Efficiency Improvements in Dry Drilling with Optimised Diamond-Like Carbon Coatings, Diamond \& Related Materials, 17:1733-1737.

13. Bi Z. M. and Wang L. (2012), Optimization of machining Processes from perspective of energy consumption: A case study, Journal of Manufacturing Systems 31, 420- 428, dx.doi.org/10.1016/j.jmsy.2012.07.002.

14. Xin Q. (2011), Diesel Engine System Design. Cambridge: Woodhead Publishing, pp.212-217.

15. Shokrani A., Dhokia V., Newman S.T. (2016), Energy conscious cryogenic machining of Ti-6Al-4V titanium alloy, Proc IMechE Part B: J Engineering Manufacture 1-17, IMechE, DOI: 10.1177/0954405416668923.

16. Gutowski T., Dahmus J. and Thiriez A. (2006), Electrical energy requirements for manufacturing processes. In: Duflou JR(ed) Proceedings of the 13th CIRP Conference on Life Cycle Engineering (LCE 2006), pp.623-627. Available at: http://www.mech.kuleu ven.be/ Ice2006/071.pdf. 